economic basis of awarding in one province, three times what is awarded for the same injury in another province?" asks Stern. "There are also many system inefficiencies that drive up costs but do not benefit the injured patient. I don't want the message out there that we're shirking our responsibility. We just want logic and equity in awarding damages across Canada."

The association is also looking for ways to reduce the length of time that cases take in an effort to mitigate legal costs, which is the second biggest expense after awards and settlements. Stern says they're continuing to work with their law firms to accelerate the pace of court action but this needs support from the justice system.

The CMPA determines its fees by forecasting the costs of providing protection in the upcoming year. In 2008, CMPA estimated the cost of protection for 2009 would be $\$ 321$ million; for 2015 , the projection is $\$ 503$ million an increase of $64 \%$.

The number of civil lawsuits actually declined by $40 \%$ between 2004 and 2013, according to the CMPA 2013 Annual Report. In 2013, there were 842 new legal cases, the lowest number in many years and well below the peak of 1415 cases in 1995. Stern says this decrease is partly due to the expense of litigation, which is causing lawyers to be more selective about the cases they take.

While suits are down, recent payment history and cost trends have "skyrocketed," according to Stern. In the past two to three years, CMPA has seen a marked increase in protection costs in Ontario and, more recently, the "rest of Canada." CMPA saw these, initially, as "blips." Settlements for cases involving compromised infants now reach $\$ 12$ to $\$ 14$ million in Ontario, so an additional five cases in one year can substantially influence the trends, says Stern.

"At three years, it's not a blip; it's something to act upon," says Stern. Given the CMPA's commitment to ensure the costs of supporting today's physicians are not deferred to the next generation of doctors, "your fiduciary requirement is to act ... it's not like you have an option."

In 2013, median damages to patients reached $\$ 161000 ; 18 \%$ higher than in 2011. Legal expenses increased $14 \%$ over 2012 , to $\$ 43000$ per case. CMPA warned the provincial and territorial medical associations in 2013 that "we were worried about cost damages going up in the rest of Canada," says Stern. It reiterated these concerns at its annual meeting. "We didn't expect it to be this high, this volatile." - Barbara Sibbald, CMAJ

CMAJ 2014. DOI:10.1503/cmaj.109-4898

\title{
MediData: How potent is medical marijuana?
}

$\mathrm{T}$ he main psychoactive component of marijuana, delta-9tetrahydrocannabinol (THC), varies in concentration from strain to strain but, in general, much of the medical cannabis that Canadian licensed growers plan to sell appears to be quite potent. In a June 2014 commentary in CMAJ, two physicians suggested that, based on available clinical evidence, prescriptions should specify that THC concentrations not exceed $9 \%$.

As can be seen on this graph, displaying the potency of the products listed on the websites of five growers, very few strains contain THC concentrations of $9 \%$ or lower, assuming these figures are accurate.

Also of note: most of the strains on the websites of growers that offer only a few products (like CanniMed and Bedrocan) have distinct THC concentrations. Those with more extensive catalogues list many strains with similar THC levels. Cannimed (5 products) told $C M A J$ that many of the strains sold by companies with wide selections are so similar - high in THC, low in cannabidiol (CBD) - that they offer no

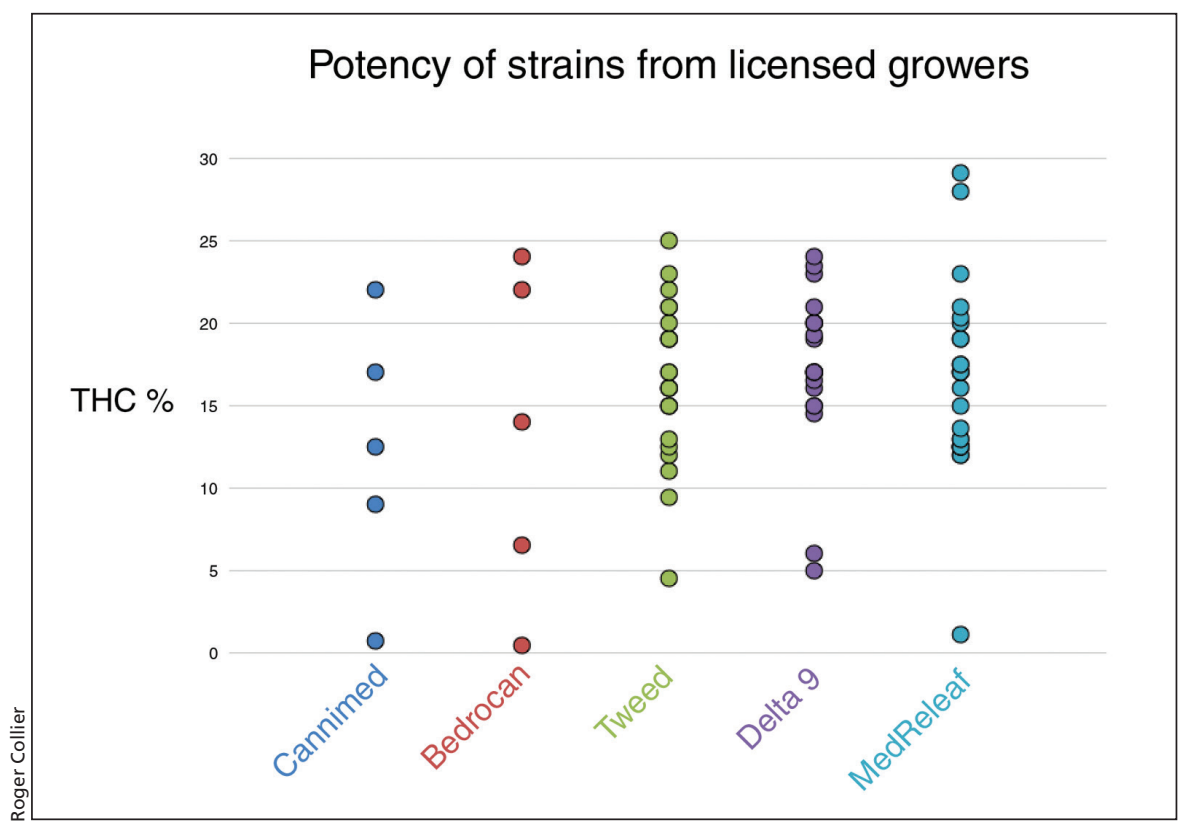

unique therapeutic benefits. But Tweed (23 products) suggested to $C M A J$ that there is much more to cannabis than just THC and CBD. There are more than 400 components in cannabis, the grower noted, and it's possible that varying those components could offer therapeutic benefits, even if THC levels are similar.
Of course, there is little clinical evidence yet to support either claim, which may explain why conversations about the specific medical benefits of marijuana tend to be peppered with a particular word: "anecdotally." Roger Collier, CMAJ 